\title{
TOKSISITAS AKUT (L 50-96 JAM) MINYAK BUMI, DISPERSAN DAN CAMPURAN KEDUANYA TERHADAP IKAN MUJAIR (Oreocbromis mossambicus)
}

\author{
Husnah")
}

\begin{abstract}
ABSTRAK
Penelitian bertujuan untuk mengetahui toksisitas akut ( $\left.\mathrm{L}_{\mathrm{c}} 50-96 \mathrm{jam}\right)$ minyak bumi, dispersan BP $1100 \mathrm{X}$ dan campuran keduanya terhadap ikan mujair (Oreochromis mossambicus) telah dilakukan di Laboratorium LEMIGAS Jakarta selama 3 bulan.

Sepuluh ekor ikan mujair masing-masing berukuran berat 0,4-0,8 gram dan panjang $3-4 \mathrm{~cm}$, diletakkan dalam wadah gelas berbentuk silinder yang berisi air laut bervolume 10 liter. Ikan tersebut diberikan perlakuan minyak bumi Kawengan dengan konsentrasi masing-masing 9.999,99; $6.812,92 ; 4.641,59 ; 3.162,28$ dan $1.467,80 \mathrm{ppm}$. Konsentrasi yang digunakan untuk perlakuan dispersan BP $1100 \mathrm{X}$ dan campuran keduanya adalah $9.999,99 ; 4.641,59 ; 2.154,43 ; 9.99,99 ; 464,16$ dan $215,44 \mathrm{ppm}$.
\end{abstract}

Uji toksisitas dilakukan dengan uji semi statis. Pengamatan kematian dilakukan pada jam ke 24, 48, 72 dan 96.

Hasil penelitian menunjukkan bahwa toksisitas akut dispersan dan campuran dispersan dan minyak bumi selama 96 jam lebih tinggi daripada minyak bumi saja.

ABSTRACT: Acute toxicity (I $\mathrm{L}_{\mathrm{c}}$ 50-96 hours) of Crude Oil, Oil Slick Dispersant and the Mixture of Both Materials on Java tilapia (Oreocbromis mossambicus), by: Husnab

An experiment to find acute toxicity of crude oil, oil slick dispersant BP $1100 \mathrm{X}$ and the mixture of both materials on mujair was conducted at the Laboratory of LEMIGAS, Jakarta for 3 months.

Ten fish with the size of 0.4-0.8 gram and 3-4 cm each were introduced in cylinder glass filled with 10 liters sea water and treated with the test material. This acute toxicity test with semi static media was renewed every 24 hours. Result shows that oils slick dispersant BP $1100 \mathrm{X}$ produced the highest acute toxicity, followed by the mixture of dispersant and crude oil.

KEYWORDS: Dipersions, tilapia

\section{PENDAHULUAN}

Meningkatnya penggunaan minyak bumi, selain dampak positifnya dirasakan oleh manusia, dapat juga menimbulkan dampak negatif terhadap lingkungan. Dampak negatif tersebut di antaranya dapat ditimbulkan sejak pengambilan, transportasi, pengolahan dan pemakaiannya. Menurut Bilal dan Muchtisar (1975), pencemaran minyak bumi yang terjadi di perairan laut Indonesia, 70 persen disebabkan oleh tanker dan kapal.

Minyak bumi dan produk sampingannya mengandung beberapa macam komponen yang berbahaya bagi kehidupan organisma laut. Di antara kompo- 
nen tersebut ada yang dapat menimbulkan pengaruh pada organisma secara perlahan-lahan (Blumer, 1974).

Usaha penanggulangan pencemaran minyak bumi dilakukan secara fisik dan kimiawi. Bentuk penanggulangan secara fisik antara lain: 1) penghalangan dan penggiringan dan 2) penyerapan. Sedangkan penanggulangan secara kimiawi antara lain penggunaan dispersan dan pembakaran. Penggunaan dispersan lebih mudah dan cepat sehingga dampak merusak minyak terhadap lingkungan dapat diperkecil (Boesch et al., 1974).

Akibat yang ditimbulkan pada pembersihan permukaan perairan yang tercemar minyak bumi dengan menggunakan dispersan lebih berbahaya daripada pen-cemaran minyak bumi itu sendiri (Amant, 1971). Dispersan serta campuran minyak dan dispersan bersifat racun (Blumer, 1974).

Salah satu cara untuk mengetahui daya racun (toksisitas) minyak bumi, dispersan dan campuran keduanya terhadap organisma adalah dengan uji biologis. Penelitian uji biologis minyak bumi telah dilakukan (Beynon dan Cowel, 1974) namun untuk dispersan serta campuran keduanya belum pernah dilakukan.

Penelitian ini dilakukan untuk mengetahui toksisitas akut minyak bumi, dispersan BP $1100 \mathrm{X}$ dan campuran keduanya terhadap ikan mujair (Oreochromis mossambicus).

\section{BAHAN DAN METODE}

Hewan uji yang digunakan adalah ikan mujair dengan ukuran berat 0,4-0,8 gram dan panjang $3.4 \mathrm{~cm}$ yang didapatkan dari tambak air payau Sunter, Ancol, Jakarta. Sebelum digunakan, hewan uji ini diaklimitasikan dahulu selama satu minggu dengan prosedur menurut APHA (1976).

Media uji adalah air laut yang diambil dari Gelanggang Samudra Jaya Ancol, Jakarta. Air laut ini kemudian disaring dengan menggunakan plankton net dan diaerasi sampai jenuh sebelum digunakan untuk percobaan.

Bahan uji yang digunakan yaitu 1) minyak bumi berasal dari sumur pengeboran Kawengan, Cepu, Jawa Tengah, 2) dispersan BP $1100 \mathrm{X}$ dan 3) campuran kedua bahan dengan perbandingan minyak dan dispersan 10:1. Wadah uji yang dipakai terbuat dari gelas berbentuk silinder dengan diameter $30 \mathrm{~cm}$ dan tinggi $40 \mathrm{~cm}$.

Uji toksisitas dilakukan dengan metode Doudoroff dan Sprague dalam Wardoyo (1979) dengan tipe uji media semi statis yang medianya diganti setiap 24 jam. Sepuluh ekor ikan uji dimasukkan ke masing-masing wadah uji yang telah berisi 10 liter air laut, kemudian diberikan perlakuan bahan uji dengan konsentrasi didapatkan dari uraian nilai ambang atas dan ambang bawah masing-masing bahan uji pada uji pendahuluan sebelumnya. Konsentrasi yang digunakan pada perlakuan minyak bumi adalah 9.999,99; 6.812,92; 4.641,59; 
$3.162,28$ dan $1.467,80 \mathrm{ppm}$. Sedangkan pada perlakuan dispersan dan campuran keduanya, konsentrasi yang digunakan adalah 9.999,99; 4.641,59; 2.154,43; 999,99; 464,16 dan 215,44 ppm.

Pada masing-masing bahan uji ditambahkan satu kontrol. Setiap konsentrasi dianggap sebagai satu perlakuan dan tiap-tiap perlakuan diulang tiga kali. Jumlah ikan yang mati dicatat pada jam ke 24, 48, 72 dan 96 . Selama percobaan berlangsung, pengukuran parameter kualitas air yang meliputi $\mathrm{pH}$, kandungan oksigen terlarut (DO), salinitas, karbon dioksida $\left(\mathrm{CO}_{2}\right)$ dan amoniak dilakukan setiap hari. Nilai toksisitas akut selama 96 jam ditentukan dengan analisis probit menurut Busvine (1971) dalam Prijono (1985).

\section{HASIL DAN PEMBAHASAN}

Hasil analisis toksisitas akut selama 96 jam $\left(\mathrm{L}_{\mathrm{c}}\right.$ 50-96 jam) minyak bumi asal Kawengan, dispersan BP $1100 \mathrm{X}$ dan campuran keduanya terdapat pada Tabel 1.

Tabel 1. Nilai $\mathrm{L}_{\mathrm{c}} 50-96$ jam minyak bumi Kawengan, dispersan BP $1100 \mathrm{X}$ dan campurannya terhadap ikan mujair

Table 1. $L_{c} 50-96$ bours values of Kawengan crude oil, dispersant BP $1100 \mathrm{X}$ and the mixture of both materials for Java tilapia

\begin{tabular}{lcc}
\hline \hline Ireatment & L, 50-96 hours (ppm) & Confidence interval (ppm) \\
\hline Kawengan Crude Oil & $1.868,13 \mathrm{a}$ & $1.553,93<\mathrm{x}<2.245,78$ \\
Dipersant BP 1100 X & $329,38 \mathrm{a}$ & $290,67<\mathrm{x}<373,24$ \\
Mixture & $377,74 \mathrm{a}$ & $246,26<\mathrm{x}<579,43$ \\
\hline \hline
\end{tabular}

Note: means in column with the same letter are not significantly differents $(P>0.05)$

Kematian ikan pada perlakuan minyak terjadi secara langsung dan tak langsung. Kematian secara tak langsung adalah sebagai akibat rendahnya konsentrasi oksigen terlarut (Lampiran 1, 2 dan 3). Rendahnya konsentrasi bahan ini terjadi akibat meningkatnya konsumsi oksigen oleh ikan, sedangkan suplai oksigen terlarut dari difusi udara ke air sedikit akibat tertutupnya permukaan air oleh lapisan minyak. Kematian secara langsung kemungkinan disebabkan oleh daya meracun senyawa aromatik pada minyak. Konsentrasi bahan ini sebelum dituangkan ke dalam air adalah 19.44 persen berat (Lampiran 4). Menurut Clarck dan Brown dalam Malins (1977), hidrokarbon aromatik mudah larut dalam air dan merupakan fraksi yang paling berbahaya dan racun kuat terhadap saraf.

Hasil penelitian Oil Pollution Control Research and Development Program (PFO) dalam Sorstrom et al. (1980) mengenai toksisitas dispersan BP $1100 \mathrm{X}$ terhadap ikan rainbow trout, nilai $\mathrm{L}_{\mathrm{c}} 50-96$ jamnya adalah $2.743 \mathrm{ppm}$. Bila 
dibandingkan dengan $\mathrm{L}_{\mathrm{c}}$ 50-96 jam dispersan pada penelitian ini yaitu 329,38 ppm, perbedaan nilai tersebut cukup besar. Besarnya perbedaan tersebut kemungkinan disebabkan oleh perbedaan temperatur media, jenis ikan dan air yang digunakan. Menurut Beynon dan Cowel (1974), temperatur air mempengaruhi laju penguapan, degradasi minyak dan dispersan serta laju kematian ikan. Pada penelitian PFO, temperatur media rata-rata $15^{\circ} \mathrm{C}$, sedangkan pada penelitian ini berkisar antara $25,9-27,0^{\circ} \mathrm{C}$.

Kematian ikan pada perlakuan dispersan juga berkaitan dengan konsentrasi oksigen terlarut dan hidrokarbon aromatik yang berasal dari pelarut dispersan. Seperti diketahui dispersan mengandung pelarut yang berfungsi memudahkan dispersan melakukan penetrasi ke dalam masa minyak. Menurut Beynon dan Cowel (1974), pelarut hidrokarbon aromatik dalam dispersan tidak boleh lebih dari 3 persen. Sedangkan konsentrasi hidrokarbon aromatik pada dispersan BP $1100 \mathrm{X}$ adalah 83 persen. Adanya pelarut ini menurut Beynon (1970) membuat dispersan menjadi lebih tinggi daya racunnya.

Pada Tabel 1 terlihat bahwa $\mathrm{L}_{c}$ 50-96 jam pada perlakuan campuran nilainya sudah mendekati $\mathrm{L}_{c}$ 50-96 jam dispersannya sendiri. Besarnya toksisitas campuran tersebut diduga sebagai akibat cara kerja meracun gabungan kedua bahan. Kematian ikan pada perlakuan campuran tidak hanya disebabkan oleh hidrokarbon aromatik pada dispersan dan minyak saja, tetapi ditentukan juga oleh daya racun gabungan kedua bahan. Adanya dispersan menyebabkan bagian minyak akan terdispersi menjadi butiran-butiran yang lebih kecil. Menurut Kunhold (1971), pada konsentrasi yang sama, minyak yang terdispersi memiliki toksisitas lebih tinggi dibandingkan lapisan minyak. Toksisitas minyak yang terdipersi akan meningkat apabila bercampur dengan dispersan.

Boesch et al. (1974) menyatakan bahwa dispersan dapat dianggap efektif bila dengan konsentrasi rendah mampu memencarkan minyak secara sempurna. Pada penelitian ini, dispersan BP $1100 \mathrm{X}$ memang mampu memencarkan minyak menjadi butiran-butiran yang lebih kecil, tetapi jumlah yang dipencarkan tidak banyak. Hal ini terlihat pada kondisi minyak sebelum dan sesudah dicampur dengan dispersan yang tidak menunjukkan perbedaan yang nyata. Pada saat pengadukan memang terlihat adanya butiran-butiran pada kolom air, tetapi beberapa saat kemudian butiran-butiran tersebut membentuk lapisan minyak di permukaan kembali. Keadaan ini menunjukkan bahwa perbandingan minyak dan dispersan 10:1 kurang memencarkan minyak, sedangkan toksisitasnya terhadap ikan cukup tinggi.

Bila nila $\mathrm{LC}_{50}$ masing-masing perlakuan dihubungkan dengan waktu kontaminasi (Lampiran 5), ternyata toksisitas semua perlakuan akan meningkat dengan semakin lamanya waktu kontaminasi. Peningkatan toksisitas pada perlakuan minyak terbesar terjadi antara jam ke 24 dan 48 . Besarnya peningkatan toksisitas pada waktu tersebut kemungkinan disebabkan oleh cara kerja meracun komponen minyak yang berbahaya seperti hidrokarbon aromatik yang bekerja dalam waktu cepat. Selain itu hidrokarbon aromatik mudah sekali 
menguap sehingga pada jam ke 48 dan 96 pengaruh racun aromatik sudah tidak ada. Kondisi ini terjadi pula pada perlakuan campuran.

\section{KESIMPULAN DAN SARAN}

Toksisitas akut selama 96 jam ( $\mathrm{L}_{\mathrm{c}} 50-96$ jam) minyak bumi asal Kawengan, dispersan BP $1100 \mathrm{X}$ dan campuran keduanya terhadap ikan mujair adalah 1.868,13; 329,38 dan 377,74 ppm. Perlakuan dispersan BP $1100 \mathrm{X}$ dan campurannya dengan minyak bumi, daya racunnya terhadap ikan mujair lebih tinggi daripada minyak bumi itu sendiri.

Mengingat konsentrasi hidrokarbon aromatik pada dispersan BP $1100 \mathrm{X}$ cukup tinggi, aplikasi bahan ini sebaiknya harus mempertimbangkan faktor lokasi pencemaran, apakah daerah tersebut merupakan wilayah yang peka atau tidak. Sebaiknya bahan ini diaplikasikan pada perairan terbuka (laut).

\section{DAFTAR PUSTAKA}

Amant S.L., 1971. The petroleum industry and its effects on marine and estuarine ecology. American Institute of Mining, Metallurgical. Petroleum Engineers, Inc.

American Public Health Association (APHA), 1976. Standard method for the examination of water and waste water. Franson, A. (ed). $14^{\text {th }}$ edition. Washington DC. p 685-869.

Beynon L.R., 1970. Oil spill dispersant. Workshop on oil spill clean-up. Mandeville. London.

Beynon L.R. and Cowel, 1974. Ecological aspect of toxicity testing of oil and dispersant. The Institute of Petroleum, Applied Science Publisher, Ltd. England. 149 p.

Bilal J. dan D.P.Muchtisar, 1975. Aspek pencemaran oleh minyak. Makalah Seminar Nasional III Hygiene Perusahaan, Kesehatan dan Keselamatan Kerja, Surabaya, 1975. Pusdiklat Lemigas. Cepu. 28 hal.

Boesch D.F., C.H.Hersner and J.H.Milgram, 1974. Oil spill and marine environment. Ballinger Publishing Company. Cambridge. 1114 p.

Blumer M., 1974. Oil contamination and living resources of the sea. In FAO Technology Conference on Marine Pollution and Its Effects on Living Resources and Fishing. Rome. 11 p.

Blumer M., H.L.Sanders, J.F.Grassle and G.R.Hampson, 1971. A small oil spill. Environment 3(2): 2-12.

Kunhold W.W., 1971. FAO. Fisheries Report no 99. FAO of United Nation. Rome. 
Malins D.C., 1977. Effects of petroleum on artict sub artict marine environment and organism. Vol. 1. Academic Press, Inc. London. 321 p.

Prijono J., 1985. Pengujian insektisida. Fakultas Pertanian. Institute Pertanian. Bogor. 56 hal.

Sorstrom S.E., I.R.Leif and H.Thor, 1980. Oil dispersants, review of effectiveness. Continental Shelf Institute. 127 p.

Wardoyo S.T.H., 1979. Panduan biologis untuk evaluasi toksisitas minyak dan dispersan. PPPTMGB. LEMIGAS. Proyek Studi Lingkungan Hidup. 56 hal. 
Lampiran 1. Nilai parameter kualitas air rata pada uji $\mathrm{L}_{\mathrm{c}}$ 50-96 jam minyak bumi terhadap ikan mujair

Appendix 1. Average value of water quality parameter on $L_{c} 50-96$ hours test of crude oil on Java tilapia

\begin{tabular}{|c|c|c|c|c|c|c|c|c|}
\hline \multicolumn{2}{|c|}{$\begin{array}{l}\text { Parameter lualitas air } \\
\text { Water quality parameters }\end{array}$} & \multicolumn{7}{|c|}{$\begin{array}{l}\text { Konsentrasi minyalk (ppon) } \\
\text { Crnde oil concentration }(p p m) \text {. }\end{array}$} \\
\hline & & Kontrol & $1.467,80$ & $2.154,43$ & $3.162,28$ & $4.641,59$ & $6.812,92$ & 99999,99 \\
\hline DO & ppm & 5,16 & 3,72 & 3,53 & 2,90 & 2,60 & 2,40 & 3,00 \\
\hline Suhu (Temperature) & ppm & 24,80 & 24,90 & 25,20 & 25,30 & 25,40 & 25,60 & 26,80 \\
\hline Salinitas (Salinity) & $0 / 00$ & 21,90 & 21,90 & 22,20 & 22,00 & 22,10 & 21,90 & 23,10 \\
\hline $\mathrm{NH}_{3}-\mathrm{N}$ & ppm & 0,22 & 0,24 & 0,22 & 0,19 & 0,24 & 0,24 & 0,27 \\
\hline $\mathrm{pH}$ & & 7,43 & 7,33 & 7,43 & 7,33 & 7,30 & 7,50 & 7,46 \\
\hline $\mathrm{CO}_{2}$ & ppm & 2,96 & 3,98 & 3,66 & 4,15 & 3,81 & 3,98 & 1,40 \\
\hline
\end{tabular}

Lampiran 2. Nilai parameter kualitas air rata pada uji $\mathrm{L}_{\mathrm{c}}$ 50-96 jam dispersan BP $1100 \mathrm{X}$ terhadap ikan mujair

Appendix 2. Average value of water quality parameter on $L_{c} 50-96$ bours test of Dispersant $B P$ $1100 \mathrm{X}$ on Java tilapia

\begin{tabular}{|c|c|c|c|c|c|c|c|c|}
\hline \multicolumn{2}{|c|}{$\begin{array}{l}\text { Parmeter lualitas air } \\
\text { Water quality parameters }\end{array}$} & \multicolumn{7}{|c|}{$\begin{array}{l}\text { Konsentrasi dispersan (ppm) } \\
\text { Dispersent concentration (ppm) }\end{array}$} \\
\hline & & Kontrol & 215,44 & 464,16 & 999,99 & $2.154,43$ & $4.614,59$ & $9.999,99$ \\
\hline DO & $\mathrm{ppm}$ & 6,27 & 4,09 & 2,66 & 2,66 & 1,93 & 1,33 & 1,80 \\
\hline Suhu (Temperature) & ppm & 25,80 & 25,90 & 26,00 & 26,30 & 26,80 & 27,00 & 27,80 \\
\hline Salinitas (Salinity) & $0 / 00$ & 19,85 & 20,20 & 20,30 & 20,43 & 20,50 & 20,10 & 19,00 \\
\hline $\mathrm{NH}_{3}-\mathrm{N}$ & $\mathrm{ppm}$ & 0,19 & 0,18 & 0,20 & 0,16 & 0,15 & 0,15 & \\
\hline $\mathrm{pH}$ & & 8,03 & 7,71 & 7,74 & 7,83 & 7,60 & 7,60 & 7,30 \\
\hline $\mathrm{CO}_{2}$ & ppm & 1,02 & 1,11 & 1,37 & 1,22 & 1,26 & 1,26 & 1,58 \\
\hline
\end{tabular}

Lampiran 3. Nilai parameter kualitas air rata pada uji $\mathrm{L}_{\mathrm{c}}$ 50-96 jam campuran minyak dan dispersan terhadap ikan mujair

Appendix 3. Average value of water quality parameter on $L_{c} 50-96$ bours test of the mixture of crude oil dan dispersant on Java tilapia

\begin{tabular}{|c|c|c|c|c|c|c|c|c|}
\hline \multicolumn{2}{|c|}{$\begin{array}{l}\text { Parameter laulitas air } \\
\text { Water quality parameters }\end{array}$} & \multicolumn{7}{|c|}{$\begin{array}{l}\text { Konsentrasi mingalk (ppm) } \\
\text { Crude oil concentration (ppm) }\end{array}$} \\
\hline & & Kontrol & 215,44 & 464,16 & 999,99 & $2.154,43$ & $4.641,59$ & 9999,99 \\
\hline 0 & ppm & 6,28 & 4,09 & 3,06 & 2,66 & 1,83 & 1,37 & 1,80 \\
\hline Suhu (Tem & ppm & 26,40 & 26,60 & 26,80 & 26,80 & 26,80 & 26,00 & 26,00 \\
\hline Salinitas (Salinity) & $0 / 00$ & 18,30 & 18,80 & 18,80 & 18,80 & 18,60 & 18,65 & 20,30 \\
\hline $\mathrm{NH}_{3}-\mathrm{N}$ & ppm & 0,18 & 0,20 & 0,18 & 0,14 & 0,11 & 0,28 & 0,33 \\
\hline $\mathrm{CO}_{2}$ & ppm & 1,20 & 2,81 & 3,08 & 2,66 & 3,09 & 3,13 & 4,16 \\
\hline
\end{tabular}


Lampiran 4. Nilai $\mathrm{LC}_{50^{\circ}} 24,48,72$ dan 96 jam minyak, dispersant dan campuran terhadap ikan mujair

Appendix 4. $L C_{5 \sigma} 24,48,72$ and 96-bour-values of crude oil, dispersant and the mixture of both materials on Java tilapia

\begin{tabular}{|c|c|c|c|c|}
\hline \multirow[t]{2}{*}{$\begin{array}{l}\text { Waktu (Jain) } \\
\text { Tume (bours) }\end{array}$} & \multicolumn{4}{|c|}{ 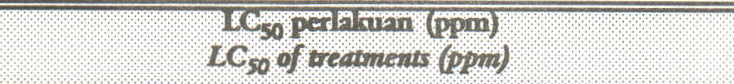 } \\
\hline & $\begin{array}{l}\text { Minyal } \\
\text { Crude oil }\end{array}$ & Dipersin & 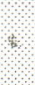 & $\begin{array}{l}\text { Campuran } \\
\text { The mirtige }\end{array}$ \\
\hline 24 & $3.129,40$ & . & & \\
\hline 48 & $1.896,84$ & - & & $1.742,21$ \\
\hline 72 & $1.895,55$ & 398,38 & & 700,37 \\
\hline 96 & $1.868,13$ & 329,38 & & 377,74 \\
\hline
\end{tabular}

Lampiran 5. Spesifikasi minyak bumi

Appendix 5. Crude oil specification

\begin{tabular}{|c|c|c|c|}
\hline $\begin{array}{l}\text { Determinasi } \\
\text { Determination }\end{array}$ & Unit & $\begin{array}{l}\text { Hesil } \\
\text { Result }\end{array}$ & Metodh \\
\hline $\begin{array}{l}\text { Berat jenis pada } 60 / 60^{\circ} \mathrm{F} \\
\text { Specific gravity at } 60 / 60^{\circ} \mathrm{F}\end{array}$ & & 0,84 & ASTM D.1298 \\
\hline $\begin{array}{l}\text { API gravity pada } 60^{\circ} \mathrm{F} \\
\text { API gravity at } 60^{\circ} \mathrm{F}\end{array}$ & & 35,90 & By conversion \\
\hline Phenol & $W t-\%$ & 0,37 & VOP 262-59 \\
\hline Parafinic & $W t-\%$ & 54,66 & LC \\
\hline Aromatic & $W t-\%$ & 19,44 & LC \\
\hline Heavy product & Wt-\% & 25,90 & LC \\
\hline
\end{tabular}

